\title{
Norms for a neuropsychological test battery to diagnose dementia in the elderly: A study from Sri Lanka
}

\author{
Srikanth Srinivasan, Qadir Jaleel \\ Department of Neurology, Lanka (Apollo) Hospitals, Colombo, Sri Lanka
}

\begin{abstract}
Aims: To pilot a neuropsychological battery for diagnosing dementia and provide normative scores in an elderly Sri Lankan sample. Materials and Methods: Consecutive subjects over the age of 60 yrs were administered tests assessing the individual domains of language, verbal episodic memory, visual perceptuospatial skills and executive functions in the Sinhala language. Results: There were a total of 230 subjects in the final sample. The mean age of the entire sample was 69 years, mean education level was 12 years and the sample comprised $53 \%$ female. One-month test-retest reliability ranged from 0.71 to 0.85 for the various tests. Most tests were significantly influenced by age and education level but not gender. The exceptions to this were some language subtests (repetition, grammar comprehension and word picture matching) and two tests of executive functioning (maze completion and alternate target cancellation), which were uninfluenced by age. The subtests where ceiling performance was attained by almost all subjects were repetition, grammar comprehension and word picture matching from the language domain, dot position discrimination from the visuospatial domain and maze completion test from the executive function domain. Scores for various tests after stratifying subjects by age and educational level are given. Conclusions: The tests were well received and could provide a basis for cognitive profiling in similar settings elsewhere.
\end{abstract}

Key words: Dementia, elderly, neuropsychology, Sri Lanka

\section{Introduction}

Testing cognition is central to dementia assessment. It is important in the early diagnosis and differential diagnosis of various dementias, monitoring progression of the disease and assessing effects of therapy. ${ }^{[1-3]}$ Various short and long batteries exist for the above purpose but very few have been validated in developing countries such as Sri Lanka. ${ }^{[4,5]}$

Such a neuropsychological battery can also been used with appropriate norms to diagnose cognitive impairment in patients with epilepsy, stroke and Parkinson's disease. In Sri Lanka as opposed to neighboring countries like

\begin{tabular}{|l|l|}
\hline \multicolumn{2}{|c|}{ Access this article online } \\
\hline Quick Response Code: & Website: \\
\hline & www.ruralneuropractice.com \\
\cline { 2 - 3 } & \\
\hline & \\
\hline
\end{tabular}

India to date there have been no such batteries that can be used to diagnose cognitive disorders.

Cross-cultural norming of neuropsychological tests can involve either adapting existing tests to suit the local population or tests can be newly developed and tested for reliability and validity. We have chosen both the above methods to develop and norm a neuropsychological battery for dementia.

We had earlier reported the development and norming of a brief cognitive screen for dementia (the Concise Cognitive Test-CONCOG) in an elderly urban Sri Lankan sample. ${ }^{[6]}$ The aim of this paper is to pilot a neuropsychological battery and provide norms stratified by demographic variables such as age and level of education.

\section{Materials and Methods}

\section{Subjects}

Participants in this study were people over the age of 60 years who had seen flyers displayed in the hospital

\section{Address for correspondence:}

Dr. Srikanth Srinivasan, Lanka (Apollo) Hospitals, Elvitigala Mawatha, Colombo - 05, Sri Lanka. E-mail: drssrikanth@gmail.com 
and had voluntarily offered to undergo the cognitive test battery. These subjects were relatives or spouses of patients attending the orthopedic or general medical outpatient departments. They were initially screened by a board certified doctor for neurological (stroke, epilepsy, head trauma or Parkinson's disease) or psychiatric disease (depression, psychosis or alcoholism) and visual or hearing impairment that might affect performance on the neuropsychological test battery. They were also administered the Concise Cognitive Test (CONCOG), a brief cognitive test, and only those scoring above $23 / 30$ were included. ${ }^{[6]}$ Depression was screened for by the Patient Health Questionnaire-2 and any participant scoring $\geq 3$ out of 6 was excluded. ${ }^{[7]}$ We did not exclude subjects with the mere presence of vascular risk factors such as hypertension, diabetes or hypercholesterolemia as that would have resulted in the creation of a "super normal" sample. All subjects gave written informed consent and the study was approved by the ethics review board of the hospital.

\section{Neuropsychological test battery}

The cognitive test battery was constructed to assess the domains of language, verbal episodic memory, visual perceptuospatial skills and executive functions as these are the most common and most important domains affected in dementias. ${ }^{[1-3]}$ The entire test battery was designed such that the administration time was less than 45 minutes. All tasks were administered in the same order to all subjects in a language of their choice (English, Sinhala or Tamil). The overwhelming majority $(>85 \%)$ of subjects had the tests administered in Sinhala language. For ease of analyses scores of subjects who had the test administered in English or Tamil have been excluded from the final sample.

The various tests included for each domain are as follows:

- Language skills: Tests were chosen to explore the individual language components such as phonology (repetition of words and phrases), syntax (grammar comprehension) and semantic skills (category verbal fluency-animals and vehicles named per minute and spoken word to picture matching). The word-picture matching subtest was adapted from the Cambridge Semantic
Battery while the other tests were constructed de novo ${ }^{[8]}$

- Episodic verbal memory: A list of eight unrelated words was presented thrice and tested for learning, free recall later and recognition from a list containing the eight original words as well as eight foils. These were adapted from the 10-66 neuropsychological battery ${ }^{[9]}$

- Visual perceptuospatial skills: Silhouette naming (10 silhouettes) and dot position discrimination subtests (10 pairs of squares with dots at varying positions) from the visual object and space perception battery were used ${ }^{[10]}$

- Executive functions: Go-no-go (adapted from the Frontal Assessment Battery), maze completion and alternate target cancellation (constructed anew) from a grid of multiple symbols were used as the executive function tests. ${ }^{[11]}$

The neuropsychological tests especially the language tests (repetition, grammar comprehension) and word list for memory testing were first translated into Sinhala, back translated into English and compared by a bilingual psychologist for accuracy in translation. They were then pilot tested on a group of 30 elderly volunteers before finalizing the test version.

\section{Statistical analyses}

Data were analyzed using Medcalc statistical software program. ${ }^{[12]}$ Correlations between performance on various tests and age and education level were calculated. The entire sample was divided into four age groups and four education groups. Means, standard deviations and $10^{\text {th }}$ percentile scores for every test for the eight groups were calculated.

\section{Results}

There were a total of 230 subjects in the final sample [Table 1]. The mean age of the entire sample was 69 years and the mean education level was 12 years. Females formed $53 \%$ of the sample. Correlational analysis revealed that most tests were significantly influenced by age and education level but not gender [Table 2]. The exceptions to this were some language subtests (repetition, grammar comprehension and word picture matching) and two

Table 1: Summary statistics for the various age and education groups

\begin{tabular}{|c|c|c|c|c|c|c|c|c|}
\hline \multirow{2}{*}{$\begin{array}{l}\text { Demographic } \\
\text { variables (years) }\end{array}$} & $N$ & Mean (SD) & $N$ & Mean (SD) & $N$ & Mean (SD) & $N$ & Mean (SD) \\
\hline & \multicolumn{2}{|c|}{$\leq 62$ years } & \multicolumn{2}{|c|}{$63-68$ years } & \multicolumn{2}{|c|}{$69-74$ years } & \multicolumn{2}{|c|}{$\geq 75$ years } \\
\hline \multirow[t]{2}{*}{ Age } & 53 & $60.6(0.8)$ & 67 & $65.6(1.7)$ & 53 & $70.9(1.6)$ & 57 & $79.7(4.5)$ \\
\hline & \multicolumn{2}{|c|}{$5-10$ year } & \multicolumn{2}{|c|}{$11-12$ year } & \multicolumn{2}{|c|}{ 13-15 year } & \multicolumn{2}{|c|}{$>15$ year } \\
\hline Education & 67 & $8.1(2.3)$ & 64 & $11.9(0.2)$ & 49 & $14.5(0.6)$ & 50 & $18.0(2.2)$ \\
\hline
\end{tabular}


tests of executive functioning (maze completion and alternate target cancellation), which were uninfluenced by age. Age had the strongest influence on word list learning and recall while education had strongest effects on word list learning, recall and semantic (category) fluency for vehicles.

A subset of 30 participants were administered the entire neuropsychological battery twice at 1 month interval and test-retest reliability was calculated. It ranged from 0.71 to 0.85 for the various tests. Inter-rater reliability was not calculated as all the tests were administered by only one of the authors (QJ).

The subtests where ceiling performance was attained by almost all subjects were repetition, word picture matching and grammar comprehension from the language domain, dot position discrimination from the visuospatial domain and maze completion test from the executive function domain.

Table 2: Correlations for various tests with age and level of education

\begin{tabular}{lcc}
\hline Cognitive tests & Age & Education \\
\hline Repetition & -0.01 & $0.18^{*}$ \\
Grammar & 0.01 & $0.27^{*}$ \\
Animals & $-0.14^{*}$ & $0.21^{*}$ \\
Vehicles & $-0.19^{*}$ & $0.34^{*}$ \\
Wpmatch & 0.01 & $0.29^{*}$ \\
Wllearning & $-0.34^{*}$ & $0.28^{*}$ \\
Wlrecall & $-0.35^{*}$ & $0.28^{*}$ \\
WIrecognition & $-0.15^{*}$ & $0.17^{*}$ \\
Silhouette & $-0.14^{*}$ & -0.05 \\
Position & $-0.15^{*}$ & $0.24^{*}$ \\
ATC errors & 0.01 & $-0.16^{*}$ \\
Go no go & $-0.17^{*}$ & $0.25^{*}$ \\
Maze errors & 0.02 & $-0.12^{*}$ \\
\hline${ }^{*} P<0.05$. ATC: Alternate target cancellation
\end{tabular}

Table 3: Age stratified scores for the various tests

\begin{tabular}{|c|c|c|c|c|c|c|c|c|c|c|c|c|}
\hline \multicolumn{13}{|c|}{ Age stratified scores } \\
\hline \multirow[t]{2}{*}{ Cognitive tests } & \multicolumn{3}{|c|}{$\leq 62$ years } & \multicolumn{3}{|c|}{$63-68$ years } & \multicolumn{3}{|c|}{$69-74$ years } & \multicolumn{3}{|c|}{$\geq 75$ years } \\
\hline & Mean & SD & $10^{\text {th }} P$ & Mean & SD & $10^{\text {th } P}$ & Mean & SD & $10^{\text {th } P}$ & Mean & SD & $10^{\text {th } P}$ \\
\hline Grammar[5] & 4.7 & 0.6 & 4.00 & 4.8 & 0.6 & 4.0 & 4.8 & 0.5 & 4.0 & 4.8 & 0.5 & 4.0 \\
\hline Repetition[6] & 6.0 & 0.1 & 6.0 & 6.0 & 0.1 & 6.0 & 6.0 & 0.0 & 6.0 & 6.0 & 0.1 & 6.0 \\
\hline Animals & 13.0 & 3.0 & 10.0 & 13.1 & 3.3 & 10.0 & 13.2 & 4.1 & 9.0 & 11.3 & 2.9 & 8.0 \\
\hline Vehicles & 11.8 & 2.6 & 9.0 & 11.9 & 2.5 & 9.0 & 10.8 & 3.1 & 7.8 & 10.1 & 1.9 & 8.0 \\
\hline Wpmatch[10] & 9.8 & 0.6 & 9.0 & 9.5 & 0.9 & 8.0 & 9.6 & 0.9 & 8.0 & 9.5 & 0.8 & 8.0 \\
\hline Wllearning[24] & 16.5 & 2.8 & 12.8 & 15.9 & 2.6 & 13.0 & 15.5 & 2.7 & 12.0 & 14.2 & 3.2 & 10.0 \\
\hline WIrecall[8] & 4.7 & 1.7 & 3.0 & 4.3 & 1.7 & 2.0 & 3.8 & 1.6 & 2.0 & 3.2 & 1.9 & 1.0 \\
\hline WIrecognition[16] & 14.6 & 2.3 & 12.0 & 14.7 & 1.4 & 13.0 & 14.3 & 1.6 & 12.0 & 14.2 & 1.7 & 12.0 \\
\hline Position[10] & 9.6 & 0.8 & 8.7 & 9.3 & 0.9 & 8.0 & 9.1 & 1.4 & 7.0 & 9.0 & 1.2 & 7.0 \\
\hline Silhouette[10] & 8.1 & 1.4 & 6.0 & 8.0 & 1.4 & 6.0 & 7.5 & 1.5 & 5.8 & 7.5 & 1.6 & 6.0 \\
\hline ATC errors & 1.4 & 4.8 & 2.2 & 0.9 & 1.4 & 2.0 & 1.8 & 4.1 & 5.2 & 2.6 & 9.9 & 4.0 \\
\hline Maze errors & 1.9 & 12.3 & 1.0 & 0.2 & 0.4 & 1.0 & 0.34 & 0.6 & 1.0 & 1.8 & 8.0 & 3.0 \\
\hline Go-no-go[10] & 9.4 & 0.9 & 8.0 & 9.2 & 1.3 & 8.0 & 8.9 & 1.4 & 6.8 & 9.0 & 1.8 & 7.0 \\
\hline
\end{tabular}

Subjects were stratified into four age groups at approximately five year intervals. They were also stratified into four educational groups according to the prevailing school educational system in Sri Lanka. Scores for subjects stratified according to age and level of education are shown in Tables 3 and 4.

\section{Discussion}

The key findings from this study were that, as expected age and education but not gender were strong predictors of performance on various neuropsychological tests. The maximal effects of these tests were seen on semantic verbal fluency tests and episodic memory. These findings are consistent with numerous other studies from different parts of the world. ${ }^{[13-20]}$

In fact, the largest normative neuropsychological study so far, the 10-66 study across India, China and Latin America, also concluded that gender had negligible effects on test performance. ${ }^{[9]}$ The strongest effect of age was on word list memory and this has also been the case with the 10-66 study. On the other hand, in the present study, education had a significant effect on semantic verbal fluency as well as memory. The study by Gureje et al. in Nigeria also showed a similar effect of education on the CERAD word list learning and recall test, which is similar to the 10-66 word list test adapted for this study. ${ }^{[14]}$ However, in the Singaporean validation of the RBANS battery, executive function tests and tests of attention were affected to the greatest degree by age and education in addition to memory. ${ }^{[16]}$ Our results are not in agreement with the above study probably because of the varying tests used for the assessment of executive skills and differing education levels. 
Table 4: Education stratified scores for the various tests

\begin{tabular}{|c|c|c|c|c|c|c|c|c|c|c|c|c|}
\hline \multicolumn{13}{|c|}{ Education stratified scores } \\
\hline \multirow[t]{2}{*}{ Cognitive tests } & \multicolumn{3}{|c|}{$5-10$ years } & \multicolumn{3}{|c|}{$11-12$ years } & \multicolumn{3}{|c|}{$13-15$ years } & \multicolumn{3}{|c|}{$>15$ years } \\
\hline & Mean & SD & $10^{\text {th } P}$ & Mean & SD & $10^{\text {th } P}$ & Mean & SD & $10^{\text {th }} P$ & Mean & SD & $10^{\text {th } P}$ \\
\hline Grammar[5] & 4.6 & 0.7 & 3.1 & 4.8 & 0.5 & 4.0 & 4.9 & 0.4 & 4.0 & 4.9 & 0.2 & 5.0 \\
\hline Repetition[6] & 6.0 & 0.2 & 6.0 & 6.0 & 0.0 & 6.0 & 6.0 & 0.0 & 6.0 & 6.0 & 0.0 & 6.0 \\
\hline Animals & 11.6 & 2.8 & 8.0 & 11.9 & 2.7 & 9.0 & 13.3 & 3.1 & 10.0 & 14.1 & 4.5 & 9.5 \\
\hline Vehicles & 10.3 & 2.3 & 8.0 & 10.5 & 2.2 & 8.0 & 11.9 & 2.4 & 9.0 & 12.5 & 3.1 & 9.5 \\
\hline Wpmatch[10] & 9.3 & 0.9 & 8.0 & 9.7 & 0.9 & 8.9 & 9.6 & 0.6 & 9.0 & 9.8 & 0.5 & 9.0 \\
\hline Wllearning[24] & 14.4 & 2.9 & 10.1 & 15.3 & 2.9 & 11.9 & 16.3 & 2.6 & 13.0 & 16.8 & 2.8 & 12.5 \\
\hline Wlrecall[8] & 3.8 & 1.9 & 1.1 & 3.8 & 1.7 & 1.0 & 4.2 & 1.8 & 2.0 & 4.4 & 1.6 & 2.5 \\
\hline WIrecognition[16] & 14.2 & 1.7 & 12.0 & 14.7 & 1.3 & 13.0 & 14.6 & 1.6 & 12.0 & 14.6 & 2.4 & 12.0 \\
\hline Position[10] & 8.9 & 1.4 & 7.0 & 9.3 & 1.0 & 7.9 & 9.6 & 0.9 & 8.4 & 9.5 & 0.9 & 8.0 \\
\hline Silhouette[10] & 7.9 & 1.7 & 5.1 & 7.8 & 1.5 & 6.0 & 7.9 & 1.3 & 6.0 & 7.6 & 1.3 & 6.0 \\
\hline ATC errors & 3.4 & 10.6 & 6.0 & 1.0 & 1.5 & 3.0 & 0.9 & 1.6 & 2.6 & 0.7 & 1.1 & 2.5 \\
\hline Go-no-go[10] & 8.6 & 1.9 & 5.0 & 9.3 & 1.1 & 8.0 & 9.5 & 0.9 & 8.0 & 9.4 & 0.8 & 8.0 \\
\hline Maze errors & 2.9 & 13.2 & 2.0 & 0.2 & 0.6 & 1.0 & 0.2 & 0.9 & 1.0 & 0.2 & 0.6 & 1.0 \\
\hline
\end{tabular}

There are a few limitations to this study. This was a relatively well-educated sample (mean years of education: $12 \mathrm{yrs}$ ) and we did not include rural elders in the test sample. This might significantly limit the applicability of this cognitive test battery to other areas of Sri Lanka and neighboring countries. Nevertheless, this sample is representative of the type of patients encountered at most private hospitals in urban areas. We also could not have tests for visual memory and praxis, which could have made the battery a comprehensive stand alone instrument. Deriving robust norms for most neuropsychological tests would mean repeat testing at yearly intervals and weeding out patients who subsequently develop mild cognitive impairment or dementia. ${ }^{[21]}$ This was not however possible in the present study which was only cross-sectional.

There was good acceptance of all these tests and there were no refusals or inability to complete for lack of understanding. This proves that most neuropsychological tests used to document cognitive impairment in dementia can be minimally adapted and used in different cultural and language settings provided the sample to be tested has an adequate education level.

To the best of our knowledge, this is the first normative study of a neuropsychological test battery in the elderly in Sri Lanka. It remains to be seen how this battery performs in similar settings within Sri Lanka and the neighboring countries.

\section{Conclusions}

We have described a neuropsychological test battery to assess cognition in the nondemented elderly and have provided normative scores for these tests. The tests themselves and the scores can be useful to anyone studying cognitive disorders in the elderly in Sri Lanka and neighboring developing countries.

\section{References}

1. Jacova C, Kertesz A, Blair M, Fisk JD, Feldman HH. Neuropsychological testing and assessment for dementia. Alzheimers Dement 2007;3:299-317.

2. Salmon DP, Bondi MW. Neuropsychological assessment of dementia. Annu Rev Psychol 2009;60:257-82.

3. Sano M. Neuropsychological testing in the diagnosis of dementia. J Geriatr Psychiatry Neurol 2006;19:155-9.

4. de Silva HA, Gunatilake SB. Mini Mental State Examination in Sinhalese: A sensitive test to screen for dementia in Sri Lanka. Int J Geriatr Psychiatry 2002;17:134-9.

5. Karunaratne S, Hanwella R, de Silva V. Validation of the Sinhala version of the Montreal Cognitive Assessment in screening for dementia. Ceylon Med J 2011;56:147-53.

6. Srinivasan S. The concise cognitive test for dementia screening: Reliability and effects of demographic variables as compared to the mini mental state examination. Neurol India 2010;58:702-7.

7. Löwe B, Kroenke K, Gräfe K. Detecting and monitoring depression with a two-item questionnaire (PHQ-2). J Psychosom Res 2005;58:163-71.

8. Adlam AL, Patterson K, Bozeat S, Hodges JR. The Cambridge Semantic Memory Test Battery: Detection of semantic deficits in semantic dementia and Alzheimer's disease. Neurocase 2010;16:193-207.

9. Sosa AL, Albanese E, Prince M, Acosta D, Ferri CP, Guerra M, et al. Population normative data for the 10/66 Dementia Research Group cognitive test battery from Latin America, India and China: A cross-sectional survey. BMC Neurol 2009;9:48.

10. Warrington EK, James M. Visual Object and Space Perception Battery (VOSP). Bury St Edmunds: Thames Valley Test Company; 1991.

11. Dubois B, Slachevsky A, Litvan I, Pillon B. The FAB: A Frontal Assessment Battery at bedside. Neurology 2000;55:1621-6.

12. MedCalc for Windows. Mariakerke, Belgium: MedCalc Software.

13. Ganguli M, Chandra V, Gilby JE, Ratcliff G, Sharma SD, Pandav R, et al. Cognitive test performance in a community-based nondemented elderly sample in rural India: The Indo-U.S. Cross-National Dementia Epidemiology Study. Int Psychogeriatr 1996;8:507-24.

14. Guruje O, Unverzargt FW, Osuntokun BO, Hendrie HC, Baiyewu O, Ogunniyi A, et al. The CERAD neuropsychological test battery: Norms from a Yoruba-speaking Nigerian sample. West Afr J Med 1995;14:29-33. 
15. Liu KP, Kuo MC, Tang KC, Chau AW, Ho IH, Kwok MP, et al. Effects of age, education and gender in the Consortium to Establish a Registry for the Alzheimer's Disease (CERAD)-Neuropsychological Assessment Battery for Cantonese-speaking Chinese elders. Int Psychogeriatr 2011;23:1575-81.

16. Lim ML, Collinson SL, Feng L, Ng TP. Cross-cultural application of the Repeatable Battery for the Assessment of Neuropsychological Status (RBANS): Performances of elderly Chinese Singaporeans. Clin Neuropsychol 2010;24:811-26.

17. Hsieh SL, Tori CD. Normative data on cross-cultural neuropsychological tests obtained from Mandarin-speaking adults across the life span. Arch Clin Neuropsychol 2007;22:283-96.

18. Das SK, Banerjee TK, Mukherjee CS, Bose P, Biswas A, Hazra A, et al. An urban community-based study of cognitive function among non-demented elderly population in India. Neurol Asia 2006;11:37-48.
19. Sahadevan S, Tan NJ, Tan T, Tan S. Cognitive testing of elderly Chinese people in Singapore: Influence of education and age on normative scores. Age Ageing 1997;26:481-6.

20. Tripathi R, Kumar JK, Bharath S, Marimuthu P, Varghese M. Clinical validity of NIMHANS neuropsychological battery for elderly: A preliminary report. Indian J Psychiatry 2013;55:279-82.

21. Holtzer R, Goldin Y, Zimmerman M, Katz M, Buschke H, Lipton RB Robust norms for selected neuropsychological tests in older adults. Arch Clin Neuropsychol 2008;23:531-41.

How to cite this article: Srinivasan $S$, Jaleel $Q$. Norms for a neuropsychological test battery to diagnose dementia in the elderly: $A$ study from Sri Lanka. J Neurosci Rural Pract 2015;6:177-81.

Source of Support: Nil. Conflict of Interest: None declared.

\section{Staying in touch with the journal}

1) Table of Contents (TOC) email alert Receive an email alert containing the TOC when a new complete issue of the journal is made available online. To register for TOC alerts go to www.ruralneuropractice.com/signup.asp.

\section{2) RSS feeds}

Really Simple Syndication (RSS) helps you to get alerts on new publication right on your desktop without going to the journal's website. You need a software (e.g. RSSReader, Feed Demon, FeedReader, My Yahoo!, NewsGator and NewzCrawler) to get advantage of this tool. RSS feeds can also be read through FireFox or Microsoft Outlook 2007. Once any of these small (and mostly free) software is installed, add www.ruralneuropractice.com/rssfeed.asp as one of the feeds. 